\title{
خصائص اللغة العربية الفصحى ومكانتها في الدين الإسلامي
}

\author{
Hasyim Asy'ari \\ hasyim.ikhac@gmail.com \\ Institut Pesantren KH. Abdul Chalim، Mojokerto
}

ملخص : اللغة العربية أفضل اللغات وأوسمها. لها الخصائص والمميزات تميزت بها عن غيرها من اللغة الأخرى. وقد تميزت اللغة العربية بميزات وخصائص انفردت بها عن سائر اللغات في النواحي التاريخية والدينية والثقافة، فضلا عن النواحي اللغوية من أصوات وصرف ونخو ودلالة وبلاغة.

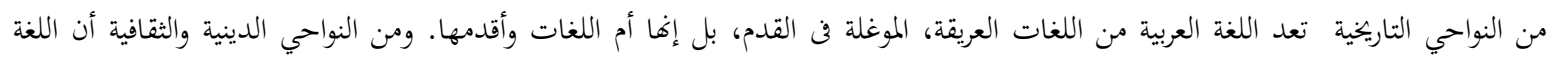

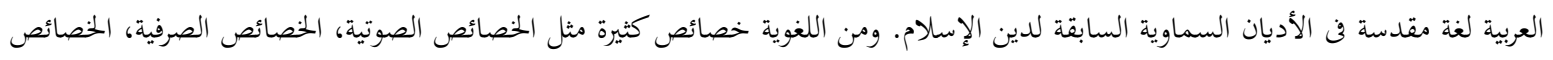
النحوية، الخصائص المعجمية والدلالية. واللغة العربية الفصحى تميزت من اللغة المولدة هو الإعراب. والعربية الفصحى تغدو لغة الأدب والثقافة.

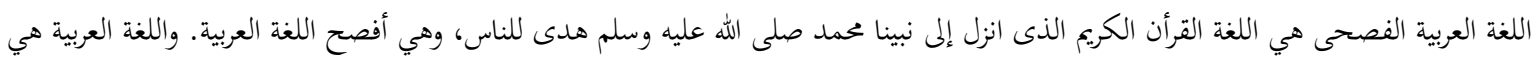
الوسيلة لحفظ التراث العقائدي والثقافي للأمة العربية الإسلامية.

الكلمات المفتاحية : العربية الفصحى، خصائص اللغة العربية، مكانة

فيه. و اللغة أنواع كثيرة، منها اللغة العببية

مقدمة

التى استخدمت في الجزيرة العربية. كانت اللغة

نشأ الانسان في الجتمع العديد، فيها

العربية من إحدى اللغات السامية التى

الثقافات و الحضارات المختلفة. ووفي تعاملهم إختفظت حتى اليوم. وفيها لهجات مختلفة

اليومية يحتاج الإنسان ليعبر ما في ذهنهم إلى بين الشعوب العربية. غيرهم، وهذه الوسيلة هي اللغة. كانت اللغة

اللغة العربية إحدى اللغات السامية وقد دورا عظيما في حياة الإنسان، لأنها أوثق العرى التى تربط بين أفراد أو جماعة. ويتواصل أطلق مصلحلح السامية في هاية القرن الثامن الإنسان باللغة مع الجمتمع الذى يولد ويعيش عشر على الشعوب الأرامية والفنيقية والعبرية 
والعربية واليمنية والبابلية الاشورية. وقد لاحظ الإطار النظري

قال ابن فارس في فقه اللغة : اللغة

العربية لغة العرب أفضل اللغات وأوسمها!

وشغل الباحثون قديما وحديثا بجصر اللغة

العربية. فنظر بعضهم إلى هذه الخصائص

على أها ميزات تميزت بها اللغة العربية عن

غيرها من اللغة الأخرى. ونظر بعضهم إليها

على أها سمات وأوصاف غلبت على اللغة

العربية أكثر مما غلبت على اللغات الأخرى.

ونظر فريق ثالث إليها على أها سمات في

العربية تشترك فيها لغات أخرى بالدرجة

نفسها.

وقد تميزت اللغة العربية بميزات

وخصائص انفردت بها عن سائر اللغات فن

النواحي التاريخية والدينية والثقافة، فضلا عن
كثير من الباحثين الأوربيين أوجه الشبة بين

$$
\text { العبرية والعربية. }
$$

اللغة العربية التي وصلت الينا هي اللغة

المشتركة في الجزيرة العربية وكانت قبل الاسلام

لهجات عديدة تعرف بلهجات القبائل وبينها

إختلاف في اللفظ كلهجات تميم وربيعة

ومضر وقيس وهديل وقصاعه وغيرها كما هو

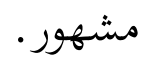

ومن هذه اللهجات المتنوعة تعتبر لهجة

القريش من أقوى اللهجات في تكوين اللغة

العربية الفصحى فقد استبكت اللهجة العربية

في صراع اللغوى نتيجة لحاجات الحياة

المتجددة التى يدفع اليها تبادل المنافع، وجمع الناس في موسم الحج والأسواق والحروب،

وقد كتب للهجة القريشية الفور لأسباب

دينية وسياسية واقتصادية.

السيوطي، المزهر في اللغة وأنواعها،

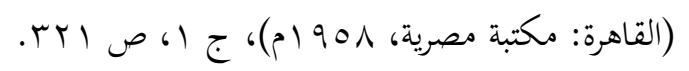


عربية بحروفها وبععاني تلك الحروف، وموافقة بترتيبها لترتيب الأبجدية العربية. يؤيد هذا الرأي ما روى عن النبي

من أن : (أول من فتق الله لسانه بالعربية

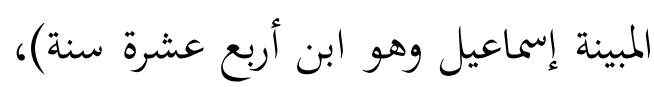

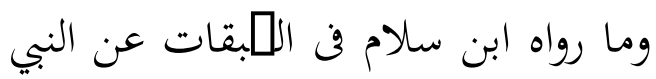
موقوفا من أن (أول من تكلم بالعربية

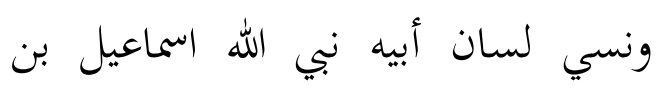
إبراهيم عليهما الصلاة والسلام).

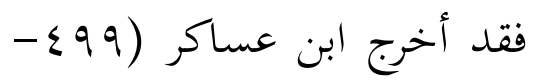

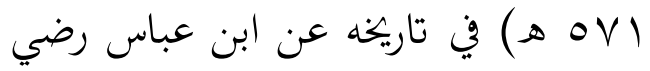

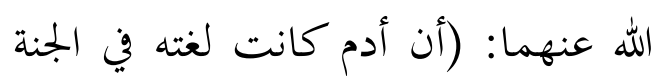
العربية، فلما عصى سلبه الله العربية، فتكلم بالسريانية، فلما تاب رد الله عليه العربية. قال السيوطي: (قال عبد الملك كالك

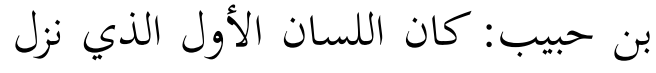

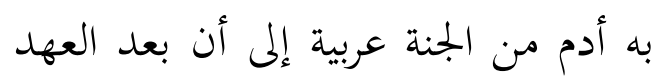
وطال، وحرف وصار سريانيان.
النواحي اللغوية من أصوات وصرف ونو ودلالة وبلاغة.

تعد اللغة العربية من اللغات

العريقة، الموغلة في القدم، بل إها أم المات اللغات وأقدمها في نظر بعض اللغويين والمؤرخين، منهم الأستاذ عباس محمود

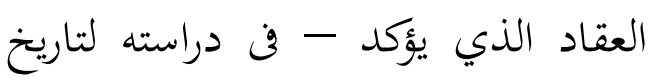
علم الإنسان - أن اللغة التى عرفت في جزيرة كريت قبل أربعة الاف سنة هي الإسيال عرفي

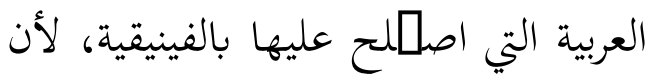
الفينيقيين أقاموا على النهرين على مقربة

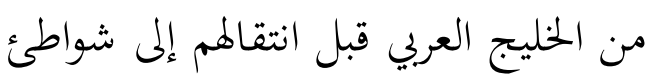
فلسلين، وأن الحروف المنسوبة إليهم كانت حروفا عربية. ويرى العقاد أن الأبجدية العربية أسبق من الأبجدية اليونانية و العبرية، فالأبجدية اليونانية

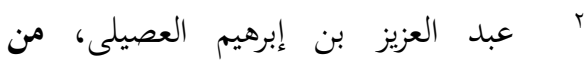

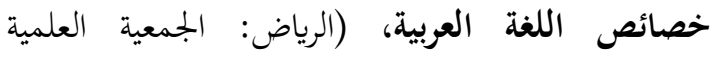
السعودية للغة العربية، ^ · . †)، ص ^ 
وإذاصحت هذه الرواية فإن اللغة العربية هي لغة الإسلام الصحيح الذي بعث الله به الرسل منذ أدم عليه السلام حتى نبينا محمد صلوات الله وسلام عليه. اللغة العربية لابد أن تكون لغة مقدسة في الأديان السماوية السابقة لدين الإسلام، قبل أن ينزل بها القرأن الكريم

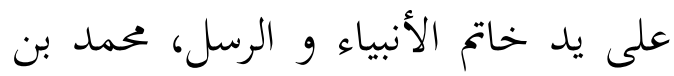
عبد الله العربي القريشي، أفصح نلتق هذه لته

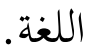

واقتضت ضرورة الدين أن تتحول هذه اللغة العربية الناطقة باسمه إلى لغة مكتوبة، فكتب بها القرأن الكريم، والأحاديث النبوة، وكتبت بها رسائل النبي محمدإلى ملوك الفرس والروم وغيرهم من الشخصيات، يدعوهم فيها إلى الإسلام ثم كتبت بها السيرة النبوة، وسائر علوم الإسلام وأدابه، من عقيدة وفقه ولغة وتاريخ، كما كتبت بها العلوم اللابيعية، كالرياضات واللب والصيدلة، وكتب بها الجغرافبا وعلوم الفلك وغيرها من العلوم

$$
\text { التي ازدهرت في العصر العباسي. }
$$

ومن العلماء من يرى أن اللغة

العربية السابقة للفصحى ترجع إلى القرن الخامس فقط قبل الميلاد، مستدلا بما ورد في النقوش الثمودية واللحيانية والصفوية، وأن أقدم نص للعربية الفصحى يرجع إلى

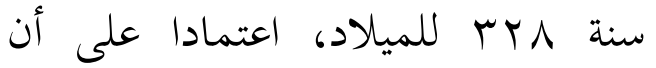
الكتابة تأتي في مرحلة لاحقة لنشأة

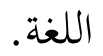

وسواء اتفق العلماء على تاريخ محدد لميلاد العربية ونشأها، أم اختلفوا فيه، فإهم يجمعون على أها من اللغات القديمة، وأغها فرع من اللغة السامية، بل هي أقرب اللغات السامية إلى اللغات السامية الأم أو هي السامية الأم، لأها احتفظت بخصائص وعناصر قديمة ترجع إلى السامية الأم أكثر محا احتفظت به الساميات الأخرى.

\section{ب. النواحي الدينية والثقافية}

ذكرت في موضع سابق ما روى

عن النبي من أن : (أول من فتق الله لسانه بالعربية المبينة إسماعيل بن إبراهيم.

• إبراهيم أنيس، في اللهجات العربية، الفاهرة:

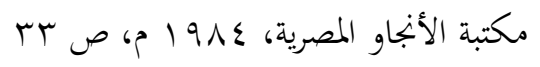


تتشخض ويتميز بعضها عن بعض في اللغات البشرية، لكن درجة هذا التميز ووضوحه يختلف من لغة لأخرى، كما تختلف اللغات في أصواتما وعدد الحروف نقاته الممثلة لهذه الأصوات.

تتميز أصوات العربية هذه بتوزعها في أوسع مدرج صوتي عرفته اللغات، حيث تتوزع في مخارجها وتتدرج ما بين الشفتين من جهة وأقصى الحلق من جهة أخرى. فالباء والفاء والواو الساكنة تخرج من الشفتين، والهمزة والهاء والعين والحاء تخرج من أقصى الحلق، تليها الغين والخاء، وتتوزع باقي الأصوات بينمها. وينبغي أن التنبيه هنا إلى أن تميز العربية

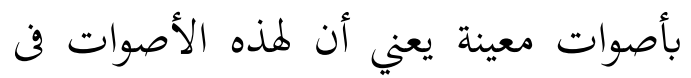
العربية وحدات صوتية متميزة وظيفيا فونولوجيا، وأن لها رموزا صوتية معينة. فصوت الصاد، الذي هو الأصوات الإطباق في العربية، ليس له مقابل في اللغة الإنجليزية وكثير من اللغات الأوروبية بوصفه صوتا مستقلا يحمل رمزا صوتيا معينا سوى
لقد ربط الإسلام بين اللغة العربية

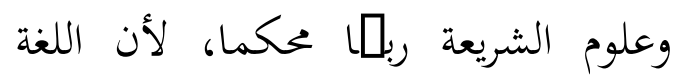
العربية محمولة على أصول الشريعة،كما يغول السيوطي، وأصبح الإجتهاد فيها مشروطا بمعرفة العربية معرفة كافة، وكما يقول إبن جني: ".. ذالك أكثر من ظل من أهل الشريعة عن القصد فيها، وحاد عن اللريقة المثلي إليها، فإنما استهواه واستخف حلمه ضعفه في اللغة الكريمة الشريفة التي خوطب الكافة بها"؛ ج. النواحي اللغوية 1. الخحائص الصوتية

الأصوات في اللغة هي مادة الألفاظ، وأساس الكالام، والعمدة في تنويع الاداء

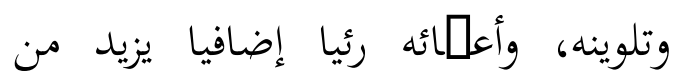
وضوح التعبير وصدقه في حمل فكرة

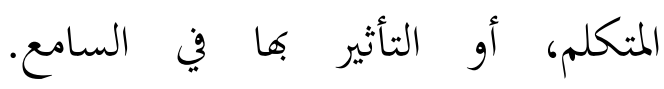
والكلمة، التي هي الوحدة الأساسية التي تتكون منها اللغة، وتتألف من عناصر هي الأصوات ممثلة في الحروف. هذه الأصوات 
صوت /s/ غير الملمق، لكنه يسمع ملابقا 2.

الصرف و ف التراث

العربيلامصلماحان لعلم واحد، بيد أن

التصريف أقدم استعمالا، وأقرب ألى المعنى

العلمي من الصرف، ولكن الصرف أكثر

استعمالا من التصريف، وبخاصة في عصرنا

الحاضر، وأخف منه على الألسنة.

أ)الاشتقاق هو : أخد صيغة من أخرى مع

اتفاقهما معنى ومادة أصلية. وهو أيضا

توليد بعض الألفاظ من بعض، والرجوع بها

إلى أصل واحد يحدد مادتها، ويوحي بمعناها

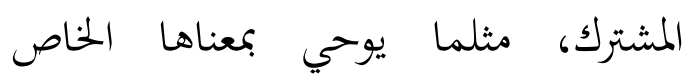

الجلديد، وتصنف أنواع المشتقات إلى ثلاث

: أصغر، الكبير، الأكبر.

ب)النحت هو انتزاع لعض الحروف من كلمتين فأكثر، وتكوين كلمة منها لتفيد

المعنى على سبيل الاحتصار.'”

9 السيوطي، المزهر في اللغة وأنواعها، ج 1)

r

أبو الفتح عثمان بن جني، الحخصائص،

$r \leqslant q$

عبد الغفار حامد هلال، العربية

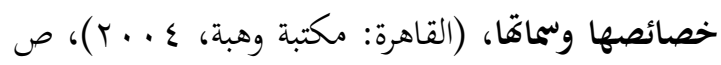

$. Y \leqslant$.
في نلمق بعض الكلمات الإنجليزية، إذا وقع some : ين مةاقع معينة، كما في son، sun، sight،science

وغيرها.

واستفاد اللغويون من هذه الميزة فن

التمييز بين الكلمات العربية والكلمات

الدخيلة او غير الفصيحة، فبينوا أن من

الفصاحة عدم الجمع بين الأصوات المتقاربة

في المخرج في كلمة واحدة، وإن جمع بين اثنين منها فإنه يقدم الأقوى على الاضعف نحو أهل وأحد وأخ وعهد.

تتميز أصوات اللغة العربية أيضا بثباتا

على مدى العصور وتعاقب الأجيال. فالحروف العربية كما نلفظها في لغتنا العربية الفصحى، ونقرأ لها القرأن الكريم - لم تتغير ولم تتبدل منذ ما يزيد على ستة عشر قرنا، أي منذ العصر الجاهلي الذي أعقبه ظهور الإسلام ونزول القرأن الكريم بهذه اللغة. 


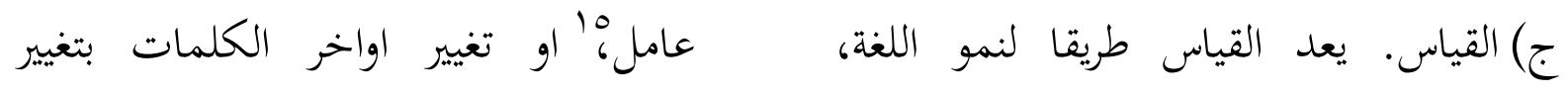
ووسيلة من وسائل إثرائها فيمكن عن وظائفها النحوية ضمن الجملة. طريقه أن تولد كلمات أو صيغ كثيرة ب)يتبين من هذا التعريفات العلاقه بين النحو لاستعمالها في أغراض شتى تبعا لمقتضيات و والاعراب، فقد يفرق بين الإعراب والنحو

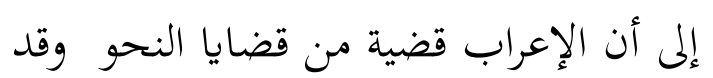

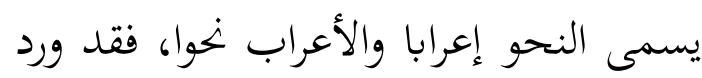
في اللسان العرب :"....والإعراب الذي هو النحو إنما هو الإبانه عن المعاني بالألفاظ. ج) التقديم والتأخير. تنقسم الجملة العربية ثلاثة اقسام :اسمية، وهي التي صدرها اسم مثل : محمد قائم. وفعلية، وهي التي صدرها فعل مثل : قام محمد. وظرفية :وهي التي صدرها ظرف او جار وبجرور مثل: اعندي ضيف ؟ ومثل: أفي الفصل طالب ؟ وتسمى شبة الجملة. ومن ابرز سمات اللغة العربية حرية التقديم و التأخير في عناصر الجملة كالخبر

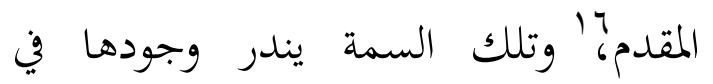

عباس حسن، النحو الوافي مع ربطه بالأساليب الرفيعة والحياة اللغوية المجددة، (القاهرة: دار الئر

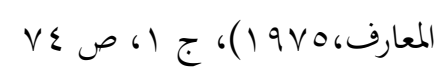
محمد بن أحمد عبد الباري الأهدل، الكواكب الدرية شح متمة الاجرومية، سورابايا:

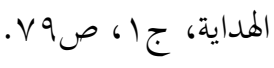

ir

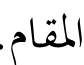

د) التعريب هو قبول اللغة العربية للكلمات والألفاظ غير العربية، ودخولها فيها وفق ضوابط محددة.' وقد عرف الإمام جلال الدين السيوطي المعرب بقوله: ( هو ما لإن استعملته العرب من الألفاظ الموضوعة

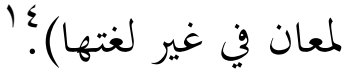
3. الحصائص النحوية أ) الإعراب، هو في اللغة إلا بانة والافصاح والتوضيح. و وي الاصلحلاح عند ابن جني هو الابانه عن المعاني بالالفاظ. وعندغيره هو تغير العلامة التي في اخر اللفظ بسبب تغير العوامل الداخله عليه وما يقتضيه كل 
على اختلاف صيغه ، نحو كان قد فعل وغير

$$
\text { ذالك. }
$$

وقد عقب برجشتراسر على هذا وقال "فاللغة العربية اكمل اللغات السامية ، واتمها في هذا الباب ، أي باب معاني الافعال الوقتية وغيرها ، وهي مع ذلك احدثها ، انكشفت انكشافا زائدا على ما في غيرها ، وابتعدت عن الاصل ابتعادا اكثر منه". و) المثنى، هو من خصائص اللغة العربية أيضا وهو :لفظ يدل على اثنين اتحدا في اللفظ والمعنى بزيادة الف ونون على المفرد رجالان 6أوياء ونون في مالتي النصب والجر نحو:رأيت رجلين ومررت برجلين وتحذف النون ويكتفي بالألف أو الياء عند الإضافة. ز) التذكير والتأنيث من السمات الخاصه باللغه العربية حيث تصنف الأشياء من ناحية
اللغة من لغات العالم ، كالإنجليزية ، والفرنسية.

د) المبني للمجهول ونائب الفاعل ، أو ما لم يسم

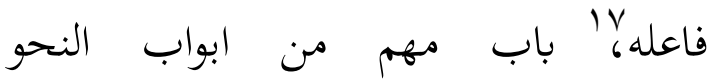
والصرف، تحدثت عنه علماء العربية بما فئم يكفي ويشفي، وهو من خصائص اللغة العربية. وقد لفتت كثير من انظار المستشرقين

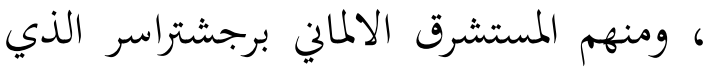
فصل القول فيه ضمن حديثه عن الجملة الفعلية ، وسماه : الفعل المعدوم الفاعل ، اونايه المسند إلية ، مبتدأ بالافعال المتعدية إلى

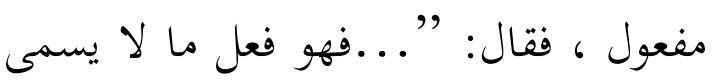

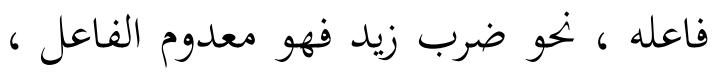
وليس بمعدوم المسند إليه. ه) أبنية الفعل، هو من الخصائص التركيبية، تخصيص ابنية الفعل وتنويعها. فقد تمها برجشتراسر : بلاريقتين، احداهما: اقتراها بالادوات نحو قد فعل، ومثل ذلك في النفي نهو لا افعل. والأخرى هي تقديم فعل كان

\footnotetext{
عبد العزيز بن إبرهيم العصيلى، من خصائص اللغة العربية، صזه

محمد بن أحمد عبد الباري الأهدل،

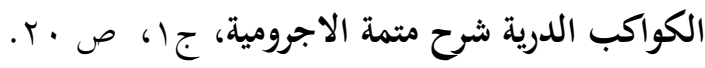

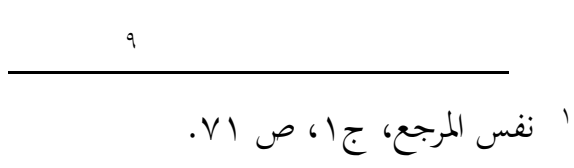


فالدكتور تمام حسن يعرف الكلمة العربية

بأها : (صيغة ذات لغوية معينة في تركيب الجملة، تقوم بدور وحدة من الوحدات

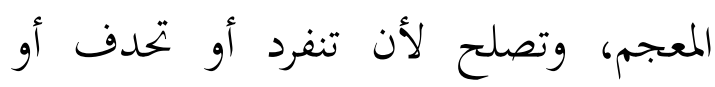
تحشى، أز يغير مةضوعها، أو يستبدل بها غيرها في السياق; وترجع في مادتا غالبا إلى لى أصول الثلاثة، وقد تلحق بما زوائد). والكلمة في أي لغة لها ثلاثة جوانب : الصيغة أو البنية، والمعنى أو الدلالة، والتوزيع. والكلمات العربية لاتخرج عن هذا القنون العام، بيد أها تمتاز عن كثير من اللغات في كل جانب من هذه الجوانب الثلاثة. فمن حيث الصيغة، تمتاز اللغة العربية بأفا لغة اشتقاقية; حيث تتغير الدلالة بتغير بنية الكلمة، مع بقاء حروفها الأصلية. ومن حيث المعنى أوالدلالة، يلاحظ أن اللغة العربية من أوسع اللغات في هذا الجانبز بسبب كثرة كلماتها، وتنوع استعمالات هذه هذه الكلمات في الميادين العلمية والأدبية والثقافة. وأما من حيث التوزيع، فإن معظم كلمات اللغة العربية ترد اسما وفعلا وصفة،

$$
\text { مع التعديل في صيغها. }
$$

الجنس إلى مذكر نهو: أب رجل وجمل

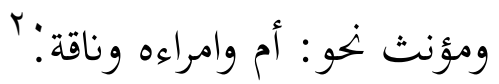
ح) الملابقة هي تلابق عنصرين أو اكثر من

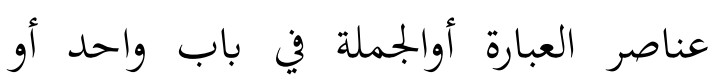
أكثر من الأبواب النحوية، وهي العلامة الإعرابية والشخص (التكلم ـ و والخلاب . والغيبه) والعدد (الإفراد والتأنيث) والتعيين (التعريف والتنكير).

\section{4. الخصائص المعجمية والدلالية}

يقصد بالخصائص المعجمية هنا كلمات اللغة، لأن الكلمة مادة المعجم، كما يقصد بالخصائص الدلالية معاني تلك الكلمات. واختلف اللغوييون في تعريف الكلمة وحدودها، 'بَّيما وحديثا: قالنحاة العرب عرفوا الكلمة بأها اللفظ المفرد، أو القول المفرد، أو لفظ مفرد دال على معنى مفرد، أو على حد قول ابن عقيل : (الكلمة لفظ وضع لمفرد).

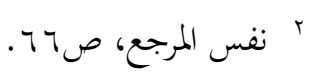
r أحمد بختار عمر، علم الدلالة، (القاهرة: مكتبة مصرية، 1991 م)، ص سمس.
} 


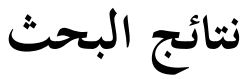

اللغة العربية الفصحى والعامية

رأينا من مواضع سابقة من هذا

الفصل أن العلماء العربية القدماء جعلوا قواعد الإحتجاج فاصلا بين مرحلتين للغة العربية. الأولى ضمت ما صح بحسب معاييرهم من كلام الجاهلين والمخضرمين والإسلاميين المتقدمين. على حين ضمت الثانية كل ما تلا هؤلاء من المولدين الذين لايحتج بكالامهم، وإن كانوا علماء أو شعراء أو كتابا تغليبا لعنصر الزمان على ما سواه، هكذا صار مصلملح "المولد" سمة للكلام الذي استعمله الناس قديما بعد عصر الرواية

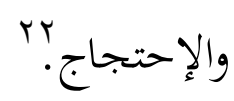

يرى يوهان فك أن ما يميز الفصحى من المولدة هو ترك الإعراب، ومن هنا يصح القول عند فك إن التحرر من الإعراب قرينة

r أمد محمد قدور، مدخل إلى فقه اللغة

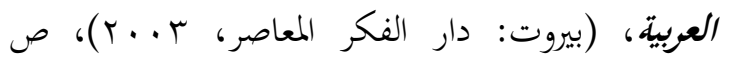

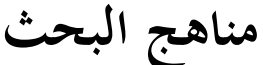

ومنهج هذا البحث هو المنهج الوصفي اللغوي. وهو يهاول أن يخلص العلوم اللغوية من الوجهة التاريخية من جهة، ومن الوجهة المعيارية من جهة أخرى. ويهتم هذا المنهج بوصف النصوص اللغوية وصفا واقعيا للنصوص. ومن هذا الوصف نصل إلى القواعد أو القوانين التي تحكم اللغة، أو نتوصل إلى معرفة البنية والتركيب الهيكلي لها. وللمنهج الوصفي أُسس عامة تتوزعها أفكار تنظيمية للمنهج , وقواعد عملية في التحليل منها : أنّ الوصف لأيّ لغة ينبغي أنْ يبدأ من الصورة المنلـوقة إلى الصورة المكتوبة والعكس خلاف ذلك باعتبار أنّ اللغة لها وجهان : وجه الكلام وهو الذي تنصرفُ إليه الوصفية بأهميةٍ خاصة , ووجه الكتابة , ولهابه فالأولى هي المادة الخام لعملية التحليل اللغوي , والأخرى هي الصورة أو الشكل

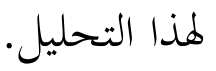


مفيدا، لأننا نميز بين الفصحى والعامية في

$$
\text { كل ما يعرض لنا من أمور. }
$$

وهكذا نجد العبية الفصحى تغدو

لغة الأدب والثقافة فقط، فلم تعد لغة الدولة، كما ام تعد لغة تتداول على ألسنة الفصحاء من الأعراب، وبذلك طرأ تحول كبير إذاغدت سفات العربية تتلقى بالتعليم المنظم الذي يتضمن القواعد والنصوص الشعرية، إضافة إلى المعين الخالد وهو القرأن الكريم الذي أسهم إسهاما عظيما في كل عصر ومصر في الحفاظ على العربية لسان الوحي المبين.

اللغة العربية الفصحى هي اللغة القرأن الكريع الذى انزل إلى نبينا محمد صلى الله عليه وسلم هدى للناس، وهي أفصح اللغة العربية. كانت اللعة العربية العامية تقابلها اللغة العربية الفصحى لخلوها عن القواعد الثابتة من التراكيب الاعرابية وهي من
أكيدة على العربية المولدة لا العكس، أي إن العربية المولدة ليست منحصرة في التحرر من الإعراب، ويرى فك أيضا أن هذه المولدة

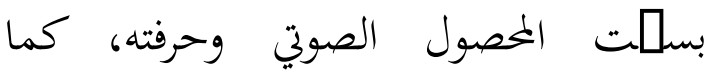
بسلت صوغ القوالب اللغوية، وأخلت بنظام الجملة وتنازلت عن التصرف الإعرابي مكتفية ببعض القواعد القليلة عن مواقع الكلمات أي رتبتها - فن الجملة عن علاقات

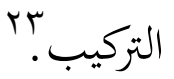
ولم تكن المؤلفات الكثيرو التي بدأت بالظهور لدى كسائي (ت 119 هـ) والتي سعت إلى إعادة هؤلاء الخارجين على الفصحى إليها، تمنع اتساع ظاهرة اللحن وانتشارها في الأمصار حتى تضافرت عوامل كثيرة جعلت اللهجات العامية المحلية تظهر

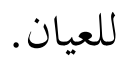
وإذا توضحت لنا حدود هذا المولد بداية وسمات ومالا، كان تتبع تاريخ العربية

$$
\text { r ن نس المربع، ص ص م10 10. }
$$


بالجمل القصيرة والكلمة الشائعة والتراكيب السهلة كما أغها تظهر اللهجة الجغرافية.

وبذلك كانت اللغة العامية لغة العامة

وهي خلاف الفصحى. والعامة هو من يتكلمون بلغة مختلفة عن الفصحى، وأن العامة من العامى يدل على أن اللفظ عندهم قريب من الجهل وبعيد من العلم الذى هو نور. وكانت العامية أسهل على المتكلم .ها من أي لغة أو لهجة مفروضة عليه.

ولذلك كانت اللغة العامية هي لغة

المعاملات اليومية في السوق، لغة التخاطب غير الرسمى، اللغة المستخدم في البيت اللغة التى يتخاطب بها صديقان حميمان، ويف لغة تستعمل الجمل القصيرة والكلمة الشائعة والتراكيب السهلة، كمأفها تظهر اللهجة الجغرافية للمتكلم، وتوجد في اللغة الواحدة
النواحى الأربعة. قد تكلمت هذه اللغة بلهجات مختلفة بين الشعوب العربية وهي لغة سهلة لخلوها من الاعراب. يتكلم اللغة العامية بلفظ شائع، ومما بالحصر أو بالتقلب الحرف التى سهل لهم عند النلق. مثلا يقول " كيف حالك " بقول "إش لونك " أو " إزيك " أو "لا بأس عليك ". بr "بك وقد يكون العامية بحدف احد الحروف من اللفظ الواحد، مثلا في قول " أحد عشر " بلفظ حد عشر (بحدف الالف). 'لوتستخدم هذه اللغة في الشؤون العادية اليومية، وهي لغة المعاملات اليومية في السوق ولغة التخاطب غيرالرسمى واللغة التى تستخدم في البيت. وقد تستعمل هذه اللغة r إميل بديع يعقوب، فقه اللغة العربية

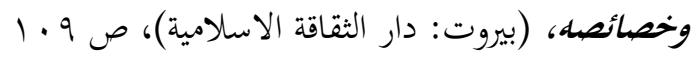

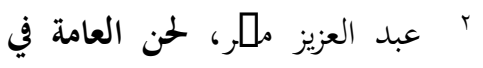
ضوء الدراسات اللغوية الحديثة، (بيروت: دار

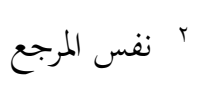

$$
\text { المعارف، (191))، ص 0ء. }
$$


العجم من جميع جهاقا"، وإن كنا نعترف

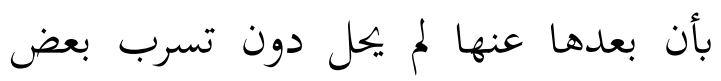
الألفاظ الفارسية والرومية إليها. ولكننا، عند الحديث عن التعريب، سنرى أن مقدر لغة ما على تمثل الكلام الأجنبي تعد مزية وخصيصة لها إذا هي صاغته على أوززاها، وصيته في قوالبها، ونفخت فيه من روحها!

ومع التشدد في مقياس الفصاحة، اصلّنع العرب لغة قريش للتفنن في القول، والإبانة في التعبير، فدل استصفاؤهم إياها على أها اختارت من كلام العرب أبينه، وراعت أرشقه، واعتمدت أصفاه; فكان حقا ما ذهب إليه الباحثون من المستشرقين وغيرهم من أن أهم مزية للعربية حفظت لها شخصيتها بين أخواتما الساميات إنما هي لعرية عزلتها عن الشعوب الأعجمية، واكتفاؤها بمقدرقا الذاتية على التعبير، وعلى التمثل والتوليد، وعلى التحير والانتقاء، وفي موطنها

$$
\text { r نفس المرجع، ص • 11. }
$$

عدة لهجات عامية، وليست لهجة عامية

$$
\text { واحدة. و و }
$$

مقاييس اللغة الفصحى

بعد أن عرضنا للفروق بين للهجتي تميم وقريش- وها اللهجان الرئيسان بين لهجات العربية- أصبح يسيرا علينا أن نتصور نوع الخصائص التي تمتاز بها لغتنا الأدبية المثالية عن أخواتا من اللغة السامية بوجه خاص، وعن كثير من اللغات الأجنبية بوجه عام ; فأن الخصائص لا تميز لغة قريش لذاتها، بل لتمثلها خير ما في اللهجات العربية الصحيحة بالتوليد والاشتقاق وخير ما في اللغات الأجنبية بالنقل والتعريب:r وينبغي ألا ننسى أن لغة قريش كانت - عند قال ابن خلدون - "بعيدة عن بلاد r السيد صبري إبراهيم، علم اللغة الاجتماعى مفهومه وقضاياه، (اسكندرية: دار المعرفة

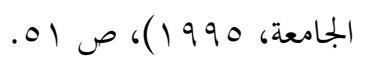
r صبحى الصالج، الدراسات في فقه اللغة،

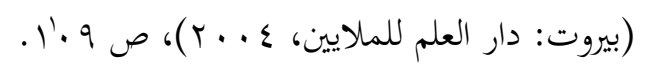


معاييرهم من كلام الجاهلين والمخضرمين والإسلاميين المتقدمين. على حين ضمت من الثانية كل ما تلا هؤلاء من المولدين الذين لايحتج بكلامهم، وإن كانوا علماء أو شعراء أو كتابا تغليبا لعنصر الزمان على ما سواه، هكذا صار مصلملح "المولد" سمة للكلام الذي استعمله الناس قديما بعد عصر الرواية

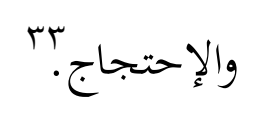

يرى يوهان فك أن ما يميز الفصحى من المولدة هو ترك الإعراب، ومن هنا يصح القول عند فك إن التحرر من الإعراب قرينة أكيدة على العربية المولدة لا العكس، أي إن العربية المولدة ليست منحصرة في التحرر من الإعراب، ويرى فك أيضا أن هذه المولدة بسلت المحصول الصوتي وحرفته، كما بسلت صوغ القوالب اللغوية، وأخلت بنظام الجملة وتنازلت عن التصرف الإعرابي مكتفية

r أحمد محمد قدور، ملدخل محمد قدور،

ملدخل إلى فقه اللغة العربية، (بيروت: دار الفكر

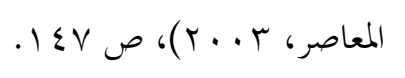

عينها، وبيئتها نفسها، وبين شقيقاتها اللهجات الفصحى التي تبادلت معها التأثر

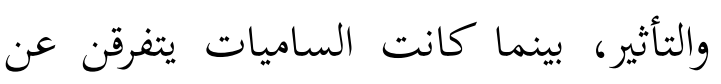
موطن السامية الأم، وييتعدن في الوقت نفسه عن الأصالة والصفاء. ولقد كان لتلك العزلة نتائج حسنة في محافظة العربية على ظاهر الإعراب الكامل، ومناسبة حروفها لمعانيها، وثبات أصواتما مع سعة مدرجها، وتنوع صرفها واشتقاقها، وتعدد أبنيتها وصيغها، وكثرة مدرجها، ونوع صرثها مصادرها وجموعها، وغنى مفرداتما والاشتراك والترادف والتضاد، واستعدادها الذاتي للنحت

$$
\text { والتوليد والتعريب. والترف والتضاد والتع }
$$

\section{اللغة العربية الفصحى والعامية}

رأينا من مواضع سابقة من هذا الفصل أن العلماء العربية القدماء جعلوا قواعد الإحتجاج فاصلا بين مرحلتين للغة

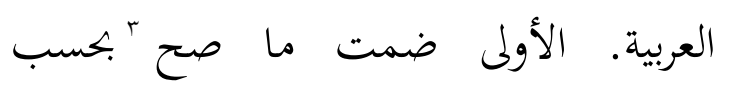
r نفس المرجع، ص 110-11 11 . 
من الأعراب، وبذلك طرأ تحول كبير إذاغدت العربية تتلقى بالتعليم المنظم الذي يتضمن القواعد والنصوص الشعرية، إضافة إلى المعين الخالد وهو القرأن الكريم الذي أسهم إسهاما عظيما في كل عصر ومصر في الحفاظ على العربية لسان الوحي المبين. اللغة العربية الفصحى هي اللغة القرأن الكريم الذى انزل إلى نبينا محمد صلى الله عليه وسلم هدى للناس، وهي أفصح اللغة العربية. كانت اللعة العربية العامية تقابلها اللغة العربية الفصحى لخلوها عن القواعد الثابتة من التراكيب الاعرابية وهي من النواحى الأربعة. قد تكلمت هذه اللغة بلهجات مختلفة بين الشعوب العربية وهي لغة سهلة لخلوها من الاعراب. يتكلم اللغة العامية بلفظ شائع، ومما بالحصر أو بالتقلب الحرف التى سهل لهم عند النلق. مثلا يقول
ببعض القواعد القليلة عن مواقع الكلمات أي رتبتها - فن الجملة عن علاقات

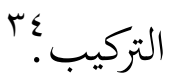
ولم تكن المؤلفات الكثيرو التي بدأت بالظهور لدى كسائي (ت 11 1 ا ه) والتي سعت إلى إعادة هؤلاء الخارجين على الى الفصحى إليها، تمنع اتساع ظاهرة اللحن وانتشارها في الأمصار حتى تضافرت عوامل كثيرة جعلت اللهجات العامية المحلية تظهر

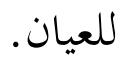
وإذا توضحت لنا حدود هذا المولد بداية وسمات ومالا، كان تتبع تاريخ العربية مفيدا، لأننا نيز بين الفصحى والعامية في

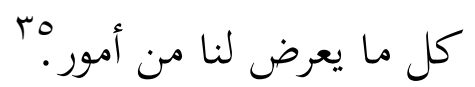
وهكذا نجد العربية الفصحى تغدو لغة الأدب والثقافة فقط، فلم تعد لغة الدولة، كما ام تعد لغة تتداول على ألسنة الفصحاء

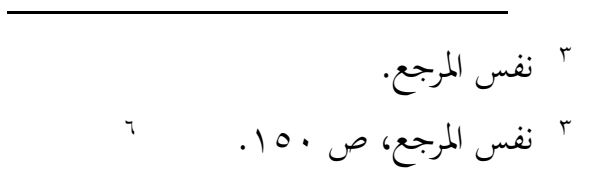


قريب من الجهل وبعيد من العلم الذى هو

نور. وكانت العامية أسهل على المتكلم بها

من أي لغة أو لهجة مفروضة عليه.

ولذلك كانت اللغة العامية هي لغة

المعاملات اليومية في السوق، لغة التخاطب

غير الرسمى، اللغة المستخدم في البيت اللغة

التى يتخاطب بها صديقان حميمان، وفي لغة

تستعمل الجمل القصيرة والكلمة الشائعة

والتراكيب السهلة، كمأهما تظهر اللهجة

الجغرافية للمتكلم، وتوجد في اللغة الواحدة

عدة لهجات عامية، وليست لهجة عامية

$$
\text { واحدة. }
$$

\section{مكانة اللغة العربية}

إن اللغة مرآة الفكر لواداته، وثمرة العقل

ونتاجه، ثم هى معرض الثقافة الإنسانية

وحضارتها، ووسيلة للتواصل البشرى يعبر بها

$$
\text { r ب تفس المرجع }
$$

؛ : السيد صبري إبراهيم، علم اللغة

الاجتماعى مفهومه وقضاياه، (اسكندرية: دار المعرفة

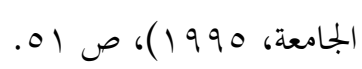

" كيف حالك " بقول "إ ش لونك " أو "

$$
\text { إزيك " أو "لا بأس عليك ". " }
$$

وقد يكون العامية بحدف احد

الحروف من اللفظ الواحد، مثلا في قول "

أحد عشر " بلفظ حد عشر (بحدف

الالف).^وتتستخدم هذه اللغة في الشؤون

العادية اليومية، وهي لغة المعاملات اليومية في

السوق ولغة التخاطب غيرالرسمى واللغة التى

تستخدم في البيت. وقد تستعمل هذه اللغة

بالجمل القصيرة والكلمة الشائعة والتراكيب

السهلة كما أها تظهر اللهجة الجغرافية.

وبذلك كانت اللغة العامية لغة العامة

وهي خلاف الفصحى. والعامة هو من

يتكلمون بلغة مختلفة عن الفصحى، وأن

العامة من العامى يدل على أن اللفظ عندهم

r إميل بديع يعقوب، فقه اللغة العربية

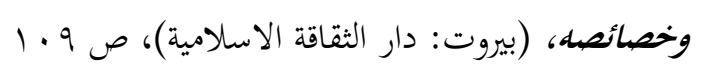

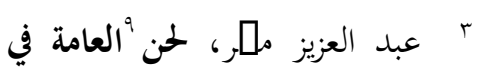

ضوء الدراسات اللغوية الحديثة، (بيروت: دار

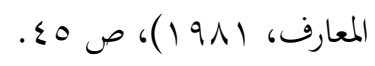


وإعراها، وتعدد [بنيتها وصيغها، و وفرة مصادرها وجموعها وجودة مفرداتما واشتقاقها والدقة في تعابيرها وتراكيبها، وفي ذلك يقول [ارنست رينان العالم الفرنسى: اإن هذه اللغة قد بلغت حد الكمال في قلب الصحراء عند [همة من الرحل ففاقت اللغات بكثرة مفرداتما، ودقة معانيها، وحسن نظام مبانيها《، كما يقول عبد الرزاق السعدي[حد]|علام اللغة والأدب: "العربية لغة كاملة معجبة تكاد تصريالفاظها مشاهد اللمبيعة، وتمثل كلماهما خلـوات النفوس، وتكاد تنجلي معانيها في

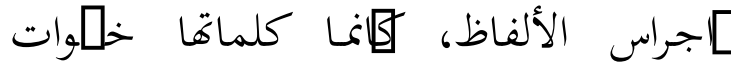
الضمير، ونبضات القلوب، و نبرات الحياة." إ)

للّغة العربية دور عظيم في حياة الأمة العربية الإسلامية، فهي وسيلة الإنسان في

؛ُ عبد الرزاق السعدي، مقومات العالمية في اللغة العربية وتحدياتما في عصر العولمة، بحث منشوريف

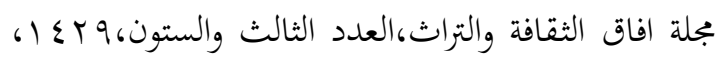
.$\Sigma \vee ص$
الإنسان عما يختلج في صدره من[فاكار ومشاعر،[اما اللغة العربية فهى واسلة عقد اللغات العالمية لمسايرتا الزمن وطواعيتها للنمو والتقدم، وقدرتا الفلـرى على التعبيرعن الذات والموجودات، وفوق ما تتصفها لغة رسالة الله الخالدة، ووعاء سنة نبيه الملههرة، ومعلم في طريق العلم، ومفتاح التفقّه في الدين، تنتمى اللغة العربية إلىلهاسرة اللغات السامية المنبثقة من مجموعـة اللغات الأفريقية الآسيوية، منها الكنعانية كما منها الآرامية والعربية، إلإن العربيتلكثر اللغات السامية تداولالإكثرها انتشارا واستخدامًا، وذلك لاحتفاظها على مقومات اللغة السامية الأم[كثرمن[ي لغة سامية [7خرى، فالعربية لغة نابضة متدفقة يتحدثها عشرات ملايين كلغة رسمية وكذلك مئات الملايين كلغة دينية، وقد تمتعت هذة اللغة بخصائصها العجيبة ومعجزاتا الفريلة منها الخصائص الصوتية والصرفية والنحوية والدلالية كما منها خصائص حروفها 
تعبر عليه الحضارة عبر الأجيال . واللغة العربية من أهم مظاهر منعة الأمة وعزتما وهي مقياس لما وصلت إليه الأمة من تقدم وتلاور، فكلما ارتقت الأمة زاد اعتمادها على اللغة وكانت لغتها قوية، وهي وسيلة فعالة من وسائل الدعوة للأمة الإسلامية بواسلتها تم جذب الكثيرين للدين الإسلامي عن طريق فنون القول في تأييد الآراء والحجج وفي دحض حجج أعداء الدين.

ولقد امتلكت اللغة العربية من الدعامات

الكبرى ما مكّنها من البقاء والنمو والحركة

والعلاء، وتتمثل هذه الدعامات في أها لغة فكر عالمي إنساني ضخم المعليات والآثار ومتصلٌ بكل قضايا الإنسان والحياة والمجتمع، ذلك هو الفكر الإسالامي الذي يتمثل في القرآن الكريم كلام الله العزيز.

معمود أحمد السيد، طرق تدريس اللغة

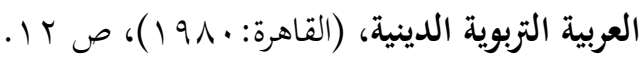

التفكير، بها يتم التواصل والتفاعل بينه وبين أفراد مجتمعه، وهي أداته للتعبير عما يجول في خاطره من أفكار وما في وجدانه من مشاعر وانفعالات، كما أهما وسيلته للتعلم والتعليم. واللغة العربية وعاء للفكر والحضارة فلا يمكن الفصل بين اللغة وبين الفكر والحضارة حيث أن اللغة هي ما في النفس وما تحصل به الفائدة سواء كان لفظاً أم خلاً، فالمعاني تقوم في النفس قبل أن ينلق بها الإنسان، والإنسان لا يفكر حتى فيما بينه وبين نفسه إلاّ في أثواب من اللغة.

الكلام لفي الفؤاد وإنما جعل اللسان على الفؤاد دليلا واللغة العربية هي الوسيلة لحفظ التراث العقائدي والثقافي للأمة العربية الإسلامية، بواسلتها تنتقل الأفكار والمعارف

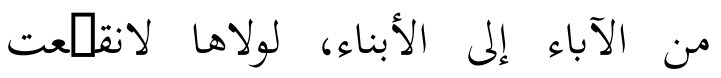
الأجيال بعضها عن بعض ولاندثرت الحضارات والسير، فهي الخزانة التي تحفظ للأمة رصيدها الفكري وهي الجسب الذي 
العرب أحب العربية، ومن أحب العربية عني كها وثابر عليها وصرف همته إليها."rاء

إذن، إن للّغة العربية أهمية ومكانة كبيرة لم تتوافر في أي لغة من لغات الشعوب الأخرى، فلغتنا العربية نرتبط بها ديناً ودنيا، فارتباطنا بها دينياً ينبع من أها لغة الإسلام الذي ارتضاه الله للناس جميعا.

الخلاصة

اللغة العربية أفضل اللغات وأوسمها.

وقد تميزت اللغة العربية بميزات وخصائص

انفردت بها عن سائر اللغات في ثلاثة النواحي. الأولى من النواحي التاريخية، وهذه النواحي تبحث عن تاريخ ظهور اللغة العربية منذ الزمان أدم أو إسماعيل عليمها السلام. والثانية من النواحي الدينية والثقافة، وهذه النواحي تبحث عن اللغة العربية هي لغة
لقد شرف الله - عز وجل - العربية

واختصها بأن كانت لغة الوحي فنزل بها القرآن هدى للعالمين ليخرج الناس من ظلمات الكفر والضلال إلى نور الحق المبين فكان الرباط الأبدي بين اللغة العربية وبين العقيدة، واكتسبت هذه اللغة قدسية خاصة ضمنت لها البقاء حية ومتجددة في كل العصور والأزمان، وأصبح التمسك بها والحفاظ عليها والذود عن حياضها وتعلمها والتحدث بها أمراً واجباً على كل مسلم. يقول عمر بن الخلهاب: " تعلموا العربية فإها من دينكم " ويقول أبو منصور. الثعالبي: "من أحب الله تعالى أحب رسوله محمدا صلى الله عليه وسلم، ومن أحب الرسول العربي أحب العرب، ومن أحب لـ

رمضان عبد التواب ، فقه اللغة وسر

العبية لأبي منصور الثعالبي، (القاهرة: مكتبة الخانجي،

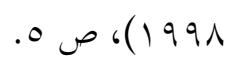


الإسلام الصحيح الذي بعث الله به الرسل، سعة مدرجها، وتنوع صرفها واشتقاقها، وأهما أستعملت لدين الله منذ القديمة في بعثة و وتعدد أبنيتها وصيغها، وكثرة مصادرها الرسل، وأهما لغة مقدسة في الأديان السماوية وبموعها، وغنى مفرداتما والاشتراك والترادف السابقة لدين الإسلام. و والثالثة النواحي والتضاد، واستعدادها الذاتي للنحت والتوليد اللغوية، وهذه النواحي تنقسم إلى بجوث والتعريب. كثيرة، منها الخصائص الصوتية، الخصائص الصرفية، الخصائص النحوية، و الخصائص المعجمية والدلالية. أن العلماء العربية القدماء المراجع جعلوا قواعد الإحتجاج فاصلا بين مرحلتين إبراهيم، السيد صبري. علم اللغة الاجتماعى مفهومه وقضاياه، للغة العربية. الأولى ضمت ما صح بحسب اسكندرية: دار المعرفة الجامعة، لماسئ معاييرهم من كلام الجاهلين والمخضرمين .1990 والإسلاميين المتقدمين. والأن نميز بين الفصحى والعامية في كل ما يعرض لنا من ابن جني أبو الفتح عثمان، الخصائص، بيروت: دار الهدى للإباعة

$$
\text { والنشر. }
$$

أنيس، إبراهيم. في اللهجات العربية. الفاهرة: مكتبة الأنجاو المصرية،

$$
.191 \varepsilon
$$

غير الرسمى. وأما مقاييس الفصحى فهي الأهدلن محمد بن أحمد عبد الباري. الكواكب الدرية شرح متمة الاجرومية. سورابايا: الهداية. العامية مختلفة عن الفصحى، هي لغة
أمور. اللغة العربية الفصحى أفصح اللغة العربية، وهي اللغة القراءن الكريم. واللغة المعاملات اليومية في السوق، لغة التخاطب محافظة العربية على ظاهر الإعراب الكامل، ومناسبة حروفها لمعانيها، وثبات أصواتما مع 
العصيلى، عبد العزيز بن إبرهيم. من

خصائص اللغة العربية. الرياض:

الجمعية العلمية السعودية للغة

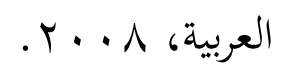

عمر، أحمد مختار. علم الدلالة. القاهرة:

$$
\text { مكتبة مصرية، 1991. } 199 \text {. }
$$

قدور، أحمد محمد. مدخل إلى فقه اللغة العربية. بيروت: دار الفكر

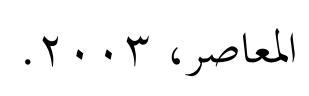

ملحر، عبد العزيز. لححن العامة في ضوء

الدراسات اللغوية الحلديثة.

بيروت: دار المعارف، 1911.

هلال، عبد الغفار حامد. العربية خصائصها وسماتما. القاهرة: مكتبة وهبة،

$$
. r \cdot s
$$

يعقوب، إميل بديع. فقه اللغة العربية

وخصائصه. يروت: دار الثقاقة

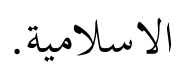

حسن، عباس. النحو الوافي مع ربطه بالأساليب الرفيعة والحياة اللغوية البجددة. القاهرة: دار

$$
\text { المعارف، 19V0 }
$$

السيوطي، جلال الدين عبد الرحمن بن أبي بكر. الدر المنثور في التفسير بالمأثور، ج. الـ بيروت: دار

$$
\text { الكتب العلمية. - الماكو، }
$$

السيوطي. المزهر في اللغة وأنواعها. القاهرة:

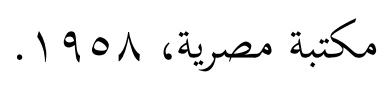

$$
\text { السعدي، عبد الرزاق. مقومات العالمية في }
$$

اللغة العربية وتحدياتما في عصر

$$
\text { العولمة. بحث منشورفي مجلة }
$$

افاق الثقافة والتراث، العدد

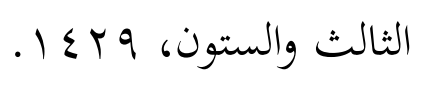

$$
\text { السيد، محمود أحمد. طرق تدريس اللغة }
$$

$$
\text { العربية التربوية الدينية. }
$$

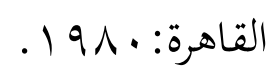

الصالج، صبحى. الدراسات في فقه اللغة. بيروت: دار العلم للملايين،

$$
. r . . \varepsilon
$$

